\title{
openheart Risk of reoperation in bioprosthetic valve patients with indication for long- term anticoagulation. Results from the observational retrospective multicentre PLECTRUM study
}

Daniela Poli, ${ }^{1}$ Emilia Antonucci, ${ }^{2}$ Vittorio Pengo, ${ }^{3}$ Elisa Grifoni, ${ }^{1}$ Niccolò Maggini, ${ }^{1}$ Sophie Testa, ${ }^{4}$ Corrado Lodigiani, ${ }^{5}$ Antonio Insana, ${ }^{6}$ Francesco Marongiu, ${ }^{7}$ Doris Barcellona, ${ }^{7}$ Carmelo Paparo, ${ }^{8}$ Eugenio Bucherini, ${ }^{9}$ Pasquale Pignatelli, ${ }^{10}$ Gualtiero Palareti, ${ }^{2}$ On behalf of the Italian Federation of Anticoagulation Clinics

To cite: Poli D, Antonucci E, Pengo V, et al. Risk of reoperation in bioprosthetic valve patients with indication for long-term anticoagulation. Results from the observational retrospective multicentre PLECTRUM study. Open Heart 2018;5:e000837. doi:10.1136/ openhrt-2018-000837

Received 16 April 2018 Revised 19 June 2018 Accepted 24 July 2018
Check for updates

(C) Author(s) (or their employer(s)) 2018. Re-use permitted under CC BY-NC. No commercial re-use. See rights and permissions. Published by BMJ.

For numbered affiliations see end of article.

Correspondence to Dr Daniela Poli; polida@aoucareggi.toscana.it

\section{ABSTRACT}

Objective Several factors should be considered when a prosthetic heart valve, bioprosthetic valve (BV) or mechanical valve is to be implanted: thrombogenicity, life expectancy and the risk of reoperation.

Methods We conducted an observational retrospective multicentre study among Italian Thrombosis Centers on patients with BV on long-term vitamin $\mathrm{K}$ antagonist (VKA) treatment to evaluate the risk of reoperation and the rate of bleeding and thrombotic events.

Results We analysed 612 patients (median age 71.8 years) with BV on long-term VKA treatment for the presence of atrial fibrillation (AF) (78.4\%) or other indications (21.6\%). Thirty-four major bleeding events (rate $1.1 \times 100$ patient-years) and 29 thromboembolic events (rate $0.9 \times 100$ patient-years) were recorded, and 46 patients (rate $1.5 \times 100$ patient-years) underwent reoperation. The rate of reoperation was higher among younger patients: $32.9 \%$ in patients $<60$ years and $3.9 \%$ in patients $\geq 60$ years (relative risk (RR) $3.8,95 \% \mathrm{Cl} 2.1$ to $7.2 ; p=0.0001$ ). When patients were analysed according to age $<65$ or $\geq 65$ years and $<75$ or $\geq 70$ years, younger patients still were at higher risk for reoperation (RR 3.1, $95 \% \mathrm{Cl} 1.7$ to 6.0 and $3.7,95 \% \mathrm{Cl} 1.7$ to 8.6 , respectively). Conclusions Our findings suggest that the threshold of 65 years for implanting a BV should be carefully evaluated, considering the high risk for reoperation and the high risk of AF occurrence with persisting need for long-term anticoagulation. The high risk for reoperation of young patients implanted with BV and the availability of a safer and easier way to conduct VKA treatment, such as the use of point-of-care devices, should be considered when the type of valve must be chosen.

\section{INTRODUCTION}

The selection of the type of valve, bioprosthetic valve $(\mathrm{BV})$ or mechanical valve (MV), in patients who need valve replacement is an important decision that seriously influences

\section{Key questions}

What is already known about this subject?

- Bioprosthetic valve duration is considered on average 15 years when implanted in elderly patients; however, the lifespan of these valves is shorter among younger patients.

- Clinical guidelines recommend the use of mechanic prosthesis in young patients.

What does this study add?

- Reoperation in young patients who have received bioprosthetic valve implantation is a frequent event.

- In our cohort the relative risk of reoperation among patients aged 6070 years was more than three times higher with respect to older patients.

How might this impact on clinical practice?

- Bioprosthetic valves are implanted to avoid the burden due to long-term anticoagulation, but the frequent occurrence of atrial fibrillation may nullify this advantage.

- These patients need to be anticoagulated with vitamin $\mathrm{K}$ antagonists.

- Self-monitoring and self-management is a safe option that should be offered to these patients.

the quality of life of patients, who should be actively involved in this choice. ${ }^{1}$ Several factors should be considered for this decision, mainly thrombogenicity, life expectancy and the risk of reoperation. Because of thrombogenicity, mechanical prostheses require lifelong anticoagulation and expose the patient to both bleeding risk and thrombus formation, particularly when anticoagulation is not well managed. On the other hand, mechanical prostheses have a longer lifespan, reducing the risk of reoperation that is the main limitation to $\mathrm{BV}$ implantation. BV 
duration is considered to be on average 15 years when implanted in elderly patients; however, the lifespan of these valves is shorter among younger patients who show accelerated valve deterioration. ${ }^{2}$ For this reason, clinical guidelines recommend the use of MV prosthesis in young patients, indicating the age of less than 60 years as the optimal age for the implantation of this kind of valve. However, uncertainty still exists for the choice of the type of valve for patients in the lifespan between 60 and 70 years, and recommendations differ from European and American guidelines. ${ }^{13}$ European guidelines recommend to use BV after the age of 65 years, ${ }^{1}$ with uncertainty for patients aged 60-65 years. Instead, American guidelines recommend the use of BV after the age of 70 years, with an interval of uncertainty for patients between 60 and 70 years. ${ }^{3}$ The use of BV has significantly increased over the last years. In the UK the number of BV implantations grows from $65.4 \%$ to $77.8 \%$ between 2004 and 2009. ${ }^{4}$ Similarly, the rate of BV implantation increased in the Netherlands between 1995 and 2010 and in the USA between 1999 and $2011^{6}$ even among patients aged 55-64 years, despite the different guideline recommendations. ${ }^{13}$

Moreover, with respect to the need for long-life anticoagulant treatment, it should be noted that a large number of elderly patients develop other indications to anticoagulation, mainly atrial fibrillation (AF), so losing the advantages of carrying a BV. ${ }^{2}$ According to the longer life expectancy that has been recorded in Western countries in the recent years, the incidence of $\mathrm{AF}$ is progressively growing particularly among patients with heart valve diseases, leading to an increasing need for anticoagulation to prevent thromboembolic stroke. Therefore, a growing number of patients who received BV implantation did not stop anticoagulation after the first few months after surgery, but are maintained on long-term treatment. We have conducted an observational, retrospective, multicentre study among Italian Thrombosis Centers on patients on long-term anticoagulation for the presence of prosthetic heart valves to obtain information on the adverse events occurring during follow-up. In this study, we report data on patients with BV on long-term vitamin $\mathrm{k}$ antagonist (VKA) treatment for the presence of AF or other indications, with the aim of evaluating the risk of undergoing reoperation and the rate of bleeding and thrombotic events during anticoagulation.

\section{METHODS}

The FCSA-START Valve Study (PLECTRUM) is an observational retrospective multicentre study performed in the frame of the START Register (Italian Survey on anTticoagulated pAtients RegisTer) (NCT02219984) ${ }^{7}$ conducted among 33 centres affiliated to the Italian Federation of Anticoagulation Clinics (FCSA). Centres were asked to select from their database patients in whom a mechanical or biological heart valve prosthesis was implanted after 1990 and who were followed for the management of anticoagulation treatment. Six hundred and twelve patients who received BV implantation and who have indication to maintain anticoagulation after the standard course of 3 months were enrolled. Patients followed by FCSA centres for anticoagulant management receive adequate education on the purpose of the treatment, the risk of complications, international normalised ratio (INR) values and drug dosage management. The centres perform periodic INR measurements, prescribe the daily VKA dosages and schedule the date for the subsequent visits; they monitor and record changes in patients' habits, diet, comedications, intercurrent illnesses, bleeding and thrombotic complications during follow-up through patient interviews. All centres take part in the specifically designed laboratory external quality control programme, which runs three times yearly and uses lyophilised plasma samples obtained from anticoagulated patients. ${ }^{8}$

\section{Patients}

Patients' demographic information and clinical data were collected. Patients were classified as hypertensive if they were taking medications to lower blood pressure. Diabetes mellitus was defined according to American Diabetes Association criteria. ${ }^{9}$ Coronary artery disease was defined on the basis of a history of myocardial infarction or stable and unstable angina. Heart failure was defined as the presence of signs and symptoms of right or left ventricular failure or both and confirmed by non-invasive or invasive measurements demonstrating objective evidence of cardiac dysfunction.

\section{Follow-up and endpoints}

In the routine practice of the participating centres follow-up visits were scheduled every 2-4 weeks for INR monitoring. Patients who missed check-ups for $>2$ months were contacted (personally or through their family or general practitioner), and the reason for interrupting treatment monitoring was recorded. In the case of death, further information about its cause was requested. Deaths for all causes were recorded. The major endpoint of the study was the occurrence of reoperation. The characteristics of these patients, the cause of reoperation and the time intercourse from the first prosthetic valve implant were recorded. Secondary endpoints were thrombotic event (stroke, transient ischaemic attack (TIA), peripheral emboli, valve thrombosis) and major bleeding. Stroke was defined as a syndrome characterised by rapidly developing clinical symptoms and/or signs of focal and at times global loss of brain function, lasting $>24$ hours, and with no apparent cause other than vascular. Ischaemic stroke was defined as a stroke with either a normal brain CT or evidence of a recent infarction in the clinically relevant area of the brain on a CT or MR scan within 3 weeks of the event, while TIA was diagnosed when neurological defects lasted $<24$ hours. Peripheral embolism was diagnosed when proved with angiography or thrombectomy. Major bleeding was defined accordingly with the definition reported by Palareti $e t a l,{ }^{10}$ taking into account 
the definition in use in Italian centres in the study period. Follow-up was stopped after the first adverse event occurred or when a patient was no longer monitored by the participating centre.

\section{Statistical analysis}

Baseline characteristics were summarised with descriptive statistics. Categorical variables were reported as counts and percentages and continuous variables were expressed as median and IQR. Incidence rates of adverse events were calculated as the number of events per 100 patientyears of observation, and rate ratios were given with their 95\% CIs. For this calculation, observation started at the beginning of follow-up and ended when patients experienced a major outcome or were censored. Analyses were performed with the Fisher's exact test (categorical data), unpaired t-test (normally distributed data) and MannWhitney test (non-normally distributed data). All variables found to be significant at univariate analysis were subsequently entered in a multivariate analysis. Risk was expressed as OR with its 95\% CI. A two-sided value of $\mathrm{p}<0.05$ was chosen for statistical significance.

The SPSS software for Windows V.20 (SPSS) and Stata V.14 statistical software package (StataCorp, College Station, TX) were used for data processing.

\section{RESULTS}

We analysed 612 patients (52.9\% men, median age 71.8 years) with BV who were on long-term VKA treatment for the presence of $\mathrm{AF}(78.4 \%)$ or other indications to anticoagulation (21.6\%). Patients were followed up for a median time of 2.4 years. The characteristics of patients are listed in table 1. During follow-up 38 patients died: 6 for major bleeding, 1 acute myocardial infarction, 1 for sudden death, 6 for sepsis, 5 for cancer, 6 for unknown reasons and 13 for heart failure. Among the patients who died of heart failure, two underwent reoperation for structural valve deterioration and died a few months later, two were implanted at 51 and 59 years, and nine after 70 years of age. For these 11 patients no information on valve deterioration is available. Thirty-four major bleeding events (rate $1.1 \times 100$ patient-years) and 29 thromboembolic events (rate $0.9 \times 100$ patient-years) were recorded. Forty-six patients $(7.5 \%$, rate $1.5 \times 100$ patientyears) undergo reoperation: 11 (24\%) for endocarditis and 35 (76\%) for structural valve deterioration (table 2). Reoperation occurred a median time of 84 months after prosthesis implantation. This interval was shorter (median time 14 months) for patients who needed reoperation for infections with respect to patients with structural valve deterioration (median time 9.2 years). The percentage of reoperation was higher among younger patients: $32.9 \%$ among patients $<60$ years and $3.9 \%$ among patients $\geq 60$ years (relative risk RR 3.8, 95\% CI 2.1 to $7.2, \mathrm{p}=0.0001$ ). When patients were analysed according to age $<65$ or $\geq 65$ years and $<70$ or $\geq 70$ years, younger patients still were at higher risk for reoperation (RR 3.1, 95\% CI 1.7 to 6.0,
Table 1 Characteristics of patients with biological heart prosthesis and adverse events during anticoagulant treatment

\begin{tabular}{|lc|}
\hline $\mathrm{n}$ & 612 \\
\hline Male (\%) & $324(52.9)$ \\
\hline Median age (range) & $71.8(24-89)$ \\
\hline Total follow-up (patient-years) & 3085 \\
\hline Median follow-up (range) & $2.4(0.5-7.5)$ \\
\hline Indications for long-term anticoagulation, $\mathrm{n}$ (\%) \\
\hline Atrial fibrillation & $480(78.4)$ \\
\hline History of stroke/TIA & $13(2.1)$ \\
\hline Cardiac diseases & $22(3.6)$ \\
\hline Other indications for VKA & $6(1.0)$ \\
\hline Unknown & $91(14.8)$ \\
\hline Clinical characteristics, $n$ (\%) & \\
\hline Hypertension & $438(71.6)$ \\
\hline Diabetes mellitus & $121(19.8)$ \\
\hline Coronary artery disease-peripheral & $246(40.2)$ \\
\hline arteriopathy & $124(20.3)$ \\
\hline Heart failure & $77(12.6)$ \\
\hline Previous stroke/TIA & $195(31.9)$ \\
\hline Antiplatelet treatment & $34(1.1)$ \\
\hline Adverse events, $\mathrm{n}$ (rate) & $29(0.9)$ \\
\hline Major bleeding & $36(1.2)$ \\
\hline Stroke/TIA & \\
\hline Death & \\
\hline
\end{tabular}

TIA, transient ischaemic attack; VKA, vitamin $k$ antagonist.

$\mathrm{p}=0.0001$ and $3.7,95 \%$ CI 1.7 to $8.6, \mathrm{p}=0.0001$, respectively). Patients who needed reoperation were similar to patients who did not for associated comorbidities, except for age and the presence of AF (table 3).

\section{DISCUSSION}

Choosing the optimal heart valve prosthesis is a challenging decision, in particular to middle-aged patients, due to the limited duration of BVs and to the increased life expectancy of the population, with a prolonged active life. The principal finding of this multicentre retrospective observational study is the confirmation that reoperation among young patients who have received BV implantation is a frequent event. In our cohort, the RR of reoperation among patients aged $60-70$ years was more than three times higher with respect to older patients. The need for reoperation after BV implantation is the consequence of infective endocarditis or of structural valve deterioration. Endocarditis affects similarly patients with $\mathrm{BV}$ and patients with $\mathrm{MV}$, with a reported risk ranging from 0.24 to $0.54 \times 100$ patient-years. ${ }^{11}$ Instead, structural valve deterioration is a rare complication among patients with MV and a frequent event among patients with BV. 
Table 2 Characteristics of patients undergoing valve prosthesis reimplantation

\begin{tabular}{|c|c|}
\hline $\mathrm{n}(\%)$ & $46(7.5)$ \\
\hline Median age (range) & $59.9(24-79)$ \\
\hline Male, n (\%) & $24(52.2)$ \\
\hline Median time interval to reimplant (months) & $84(1-312)$ \\
\hline \multicolumn{2}{|l|}{ Site of first implantation, $\mathrm{n}(\%)$} \\
\hline Aortic & $30(65.2)$ \\
\hline Mitral & $14(30.4)$ \\
\hline Mitroaortic & $2(4.3)$ \\
\hline Median time interval to reoperation (months) & $84(1-312)$ \\
\hline \multicolumn{2}{|l|}{ Cause of reoperation, $\mathrm{n}(\%)$} \\
\hline Infection & $11(23.9)$ \\
\hline Prosthetic valve deterioration & $35(76.1)$ \\
\hline \multicolumn{2}{|l|}{ Median time interval to reimplant, months (range) } \\
\hline Due to infection & $14(2-72)$ \\
\hline Due to valve deterioration & $114(1-312)$ \\
\hline \multicolumn{2}{|l|}{ Median age of patients, years (range) } \\
\hline With infections & $69.8(31-78)$ \\
\hline With structural valve deterioration & $55.8(24-79)$ \\
\hline
\end{tabular}

BVs have an expected life of average 15 years. ${ }^{2}$ A rate of reoperation due to structural valve deterioration has been reported in $1.9 \%$ of patients after 10 years and in $15 \%$ at 20 years. ${ }^{12}$ Accordingly, a study from Chiang et $\mathrm{l}^{13}$

Table 3 Clinical characteristics of patients with and without reoperation

\begin{tabular}{|lccl|}
\hline & $\begin{array}{l}\text { Patients } \\
\text { without } \\
\text { reoperation } \\
\text { (n=567) }\end{array}$ & $\begin{array}{l}\text { Patients } \\
\text { with } \\
\text { reoperation } \\
\text { (n=45) }\end{array}$ & $\begin{array}{l}\mathbf{P} \\
\text { values }\end{array}$ \\
\hline Median age (range) & $72.6(27-89)$ & $56.7(24-79)$ & 0.0001 \\
\hline Valve position, $\mathrm{n}(\%)$ & & & \\
\hline Aortic & $335(59.1)$ & $29(64.4)$ & \\
\hline Mitralic & $157(27.7)$ & $14(31.1)$ & \\
\hline Both & $75(13.2)$ & $2(4.5)$ & 0.2 \\
\hline Comorbidity, $\mathrm{n}$ (\%) & & & \\
\hline Hypertension & $402(70.9)$ & $36(80.0)$ & 0.4 \\
\hline Diabetes mellitus & $110(19.4)$ & $11(24.4)$ & 0.6 \\
\hline Coronary artery & $131(23.1)$ & $13(28.9)$ & 0.5 \\
\hline disease & & $30(66.7)$ & 0.05 \\
\hline Atrial fibrillation & $450(79.4)$ & $8(17.8)$ & 0.3 \\
\hline Previous stroke/TIA & $69(12.2)$ & $11(24.4)$ & 0.7 \\
\hline Heart failure & $113(19.9)$ & $1 / 26(3.8)$ & 1.0 \\
\hline eGFR <30 mL/min & $12 / 273(4.4)$ & $12(26.7)$ & 0.4 \\
\hline Smoking habitus & $118(20.8)$ & $10(22.2)$ & 0.2 \\
\hline Antiplatelet treatment & $185(32.6)$ & & \\
\hline
\end{tabular}

eGFR, estimated glomerular filtration rate; TIA, transient ischaemic attack. reported a rate of reoperation of $12.1 \%$ after 15 years. More recently, Goldstone et $a l^{14}$ reported a percentage of reoperation of $14.8 \%$ among patients aged $<70$ years, similarly to the percentage recorded in our study. Reoperation carries a high mortality rate, ${ }^{131516}$ even if the use of minimal access approaches may reduce this risk. Similarly, the recent availability of the technique of valve-invalve procedure in patients with structural valve deterioration is an option to be considered to lower the risk of reoperation. ${ }^{1718}$ However, there is limited experience with this procedures and long-term follow-up is limited. ${ }^{19}$

When an MV is implanted the need for reoperation is rare $^{1420}$; however, long-term anticoagulation is required to avoid thrombus formation. The bleeding risk associated with anticoagulation is a limitation to use of MVs, influencing patients and physicians' choice. Bleeding risk is reduced when anticoagulation intensity is lower ${ }^{21}$ and when adequate INR monitoring is achieved. ${ }^{22}{ }^{23}$ With the introduction of direct oral anticoagulants (DOAC), which showed to be non-inferior to VKAs for stroke prevention with a significant lower bleeding risk in patients with $\mathrm{AF}$, it was expected a similar improvement even in patients with prosthetic heart valves. However, the results of RE-ALIGN trial ${ }^{24}$ demonstrated an increase of both bleeding and thrombotic risks among patients with $\mathrm{MV}$, leading to the premature stopping of the trial. At the moment, no large randomised trials on the use of DOACs in patients with MV are ongoing and these patients need to be anticoagulated with VKAs. Therefore, with increased frequency BVs are implanted to avoid the burden due to long-term anticoagulation. The frequent occurrence of $\mathrm{AF}$ may nullify this advantage. AF is a frequent cardiac arrhythmia at high embolic risk and there is strong evidence of the advantage of anticoagulation for stroke prevention. ${ }^{25}$ Its incidence is growing with age and there are no studies that evaluate the outcomes of patients with $\mathrm{BV}$ already on anticoagulation because of $\mathrm{AF}^{2}$ even if it should be noted that these patients, although different from MV patients, can be treated also with DOACs. ${ }^{25}$ VKAs have been demonstrated to be highly effective in the prevention of thromboembolism among patients with MVs and are still used by millions of patients worldwide. ${ }^{26}$ It has been well defined that a strong association exists between the quality of anticoagulation control, evaluated as time in therapeutic range (TTR), ${ }^{27}$ and the occurrence of adverse events. ${ }^{28}$ Among patients with MV on long-term VKA treatment the direct involvement of the patient itself in the management of the anticoagulation has been successfully reported. The availability of accurate point-of-care devices allows the self-testing by the patients, who can have the INR results managed by the responsible physician (self-testing) or can be trained to adjust the drug dosage according to the INR results (self-management). This modality has been widely used in Germany due to the availability of reimbursement for these devices in this country. A higher TTR was obtained among patients on self-management compared with patients on routine care monitoring. ${ }^{29}$ Moreover, it has 
been reported that self-monitoring was superior to usual care with $49 \%$ (HR $0.51,95 \%$ CI 0.31 to 0.85 ) risk reduction of thromboembolic events. ${ }^{30}$ The advantage over the routine care was higher mainly among younger patients and particularly in those with MVs. ${ }^{30}$ Patients with MV are younger than patients on VKAs for other indications, and are highly aware of thromboembolic risks, with particular willingness to simplify their treatment and have a better quality of life. It should be noted that bleeding rates are not reduced among patients on self-monitoring, and no major effect on mortality has been reported. ${ }^{22}$ Several studies show that self-monitoring and self-management is a safe option for suitable patients and this is an option that should be offered to all patients who need long-term VKA treatment. ${ }^{22}$

\section{LIMITATIONS}

We are aware of the limitations of our study. First, this is an observational retrospective cohort study, and therefore we could not adjust for clinical information that was not recorded. Second, our observation excluded patients without indication to long-term anticoagulation. Therefore, we cannot evaluate the outcome of these patients. Third, for 11 patients no information on valve deterioration was available.

The strengths of our study are the multicentre design, and the prospective recording of the adverse events and of anticoagulation history routinely done by participating centres in electronic databases.

In conclusion, our findings suggest that the threshold of 65 years for implanting a BV should be carefully evaluated, considering the high risk for reoperation and the high risk of AF occurrence with persisting need for longterm anticoagulation. The high risk for reoperation of young patients implanted with BV and the availability of a safe and easy way to conduct VKA treatment should be considered when the type of valve must be chosen.

\author{
Author affiliations \\ ${ }^{1}$ Thrombosis Centre, Azienda Ospedaliero-Universitaria Careggi, Florence, Italy \\ ${ }^{2}$ Arianna Anticoagulazione Foundation, Bologna, Italy \\ ${ }^{3}$ Department of Cardiac Thoracic and Vascular Sciences, Thrombosis Centre, \\ University of Padova, Padova, Italy \\ ${ }^{4}$ Haemostasis and Thrombosis Centre, Hospital of Cremona, Cremona, Italy \\ ${ }^{5}$ Humanitas Research Hospital, IRCCS Rozzano-Milano, Milan, Italy \\ ${ }^{6}$ Servizio Di Patologia Clinica Ospedale S. Croce Moncalieri, Moncalieri, Italy \\ ${ }^{7}$ Centro Emostasi, Azienda Ospedaliero Universitaria di Monserrato, Cagliari, Italy \\ ${ }^{8}$ Centro Anti Trombosi Ospedale Maggiore, Chieri, Italy \\ ${ }^{9}$ U.O. Cardiologia Ospedale Per gli infermi, Faenza, Italy \\ ${ }^{10}$ Dipartimento di Medicina Interna, Università La Sapienza Roma, Rome, Italy
}

Acknowledgements List of participating centres: DP: Centro Trombosi SOD Malattie Aterotrombotiche Azienda Ospedaliero Universitaria Careggi, Firenze; ST, Oriana Paoletti: Dipartimento di Medicina di Laboratorio Centro Emostasi e Trombosi, ASST Cremona; CL, Paola Ferrazzi, llaria Quaglia: Centro Trombosi e Malattie Emorragiche, Humanitas Research Hospital, IRCCS Rozzano-Mi; Nadia Coffetti, Rosa Marotta, Varusca Brusegan, Orazio Bergamelli, Servizio di Immunoematologia e Medicina Trasfusionale Azienda Ospedaliera Bolognini, ASST Bergamo Est, Seriate e Ambulatorio TAO SIMT Ospedale Fernaroli, Alzano Lombardo; Roberto Facchinetti: Laboratorio Analisi Azienda Ospedaliera Universitaria Integrata (AOUI) Ospedale Civile Maggiore Di Borgo Trento, Verona;
Giuseppina Serricchio, Silvia Sarpau, Francesca Brevi, ASST Lariana Como; Pietro Falco, Guarino Silverio: Poliambulatorio Specialistico MEDICAL PONTINO, Latina; Catello Mangione, Giacomo Bellomo: Servizio Immunotrasfusionale 0spedale 'Santa Caterina Novella' Galatina (LE); Serena Masottini, Alessandra Cosenza: Centro per la prevenzione, diagnosi e trattamento delle malattie tromboemboliche-Asl 8, Cagliari; Lucia Ruocco, Paolo Chiarugi, Monica Casini: Ambulatorio Antitrombosi CAT-TAO AOU, Pisana; Arturo Cafolla, Antonietta Ferretti, Ematologia, UOS Emostasi e Trombosi, Policlinico Umberto I ${ }^{\circ}$, Roma; Giorgia Micucci, Serena Rupoli, Lucia Canafoglia: Azienda Ospedaliero-Universitaria Ospedali Riuniti Di Ancona; Paolo Pedico, Rita Galasso, Rosa Rotunno: UO Medicina Trasfusionale Ospedale Mons Raffaele Dimiccoli, Barletta; Al, Paolo Valesella, Servizio Di Patologia Clinica Dipartimento Dei Servizi-0spedale S Croce Moncalieri, Moncalieri (T0); Angelo Santoro: UOC Patologia Clinica e Centro Trombosi, Presidio Ospedaliero 'A Perrino', ASL Brindisi; FM, DB: Centro Di Fisiopatologia dell'Emostasi e Terapia Anticoagulante Azienda Ospedaliero Universitaria di Monserrato, Cagliari; VP, Gentian Denas: Istituto di Cardiologia, Policlinico Universitario, Università di Padova; CP: Centro Anti Trombosi Ospedale Maggiore ASL T05, Chieri (T0); EB, Flavia Tani, Enrico Carioli: Centro di Sorveglianza per la Terapia Anticoagulante, Angiologia-Medicina Vascolare UO Cardiologia Ospedale Civile per gli infermiFaenza (RA); PP, Daniele Pastori, Tommasa Vicario: Dipartimento di Medicina Interna e specialità mediche, Università La Sapienza Roma; Lucilla Masciocco, Pasquale Saracino, Angelo Benvenuto: UOC Medicina Interna, Centro Controllo Coagulazione, Ospedale Lastaria, Lucera (FG); Anna Turrini, Stefano Ciaffone; Ospedale 'SACRO CUORE' Laboratorio Analisi Cliniche e Medicina Trasfusionale Negrar (VR); Andrea Toma, Pietro Barbera UOC di Patologia Clinica Arzignano (VI); Paolo Gresele, Tiziana Fierro, Stefano Pasquino: Department of Medicine, Section of Internal and Cardiovascular Medicine, University of Perugia; Lucia La Rosa, Rino Morales Centro Trasfusionale e ambulatorio Emostasi e Trombosi, ASST Vimercate, Francesco Ronchi: Giuseppe Isu Centro TAO Servizio Di Patologia Clinica Ospedale Ns Signora Di Bonaria Asl 6 Sanluri (Ca); Teresa Lerede, Luca Barcella Centro Trombosi e Emostasi Immunoematologia e Medicina Trasfusionale ASST Papa Giovanni XXIII Bergamo; Luigi Ria: Centro Trombosi ed Emostasi, UOC di Medicina Interna, Ospedale ‘Sacro Cuore di Gesù' Gallipoli, ASL Lecce (LE); Rosanna Crisantemo, Luciano Suriano, Luciano Lorusso: Mario De Sarlo Servizio di Immunoematologia e Medicina Trasfusionale 0spedale L Bonomo Andria (BA); Pasquale Carrato Istituto Polidiagnostico Santa Chiara, Agropoli (SA); Carmine Oricchio UOS Centro Trasfusionale del PO ‘Luigi Curto' di Polla-ASL Salerno; Elvira Grandone, Donatella Colaizzo: Centro Trombosi, IRCCS Casa Sollievo della Sofferenza, S Giovanni Rotondo (FG); Maurizio Molinatti Unità Funzionale di Ematologia Centro TAO Humanitas Cellini (T0)

Contributors DP designed the study, collected the data, analysed and interpreted the data, and drafted the manuscript. EA collected the data, analysed and interpreted the data, and drafted the manuscript. EG, NM, ST, CL, DB, Al, FM, CP, $\mathrm{EB}$ and PP contributed to the data collection. VP and GP revised the draft of the manuscript critically for important intellectual content and finally approved the submitted manuscript.

Funding The authors have not declared a specific grant for this research from any funding agency in the public, commercial or not-for-profit sectors.

Competing interests None declared.

Patient consent Next of kin consent obtained.

Ethics approval Institutional review boards of the participating registries.

Provenance and peer review Not commissioned; internally peer reviewed.

Data statement № additional data are available.

Open access This is an Open Access article distributed in accordance with the Creative Commons Attribution Non Commercial (CC BY-NC 4.0) license, which permits others to distribute, remix, adapt, build upon this work non-commercially, and license their derivative works on different terms, provided the original work is properly cited and the use is non-commercial. See: http://creativecommons.org/ licenses/by-nc/4.0

\section{REFERENCES}

1. Baumgartner H, Falk V, Bax JJ, et al. 2017 ESC/EACTS Guidelines for the management of valvular heart disease. Eur Heart $J$ 2017;38:2739-91.

2. Head SJ, Çelik M, Kappetein AP. Mechanical versus bioprosthetic aortic valve replacement. Eur Heart J 2017;38:2183-91.

3. Nishimura RA, Otto CM, Bonow RO. 2014 AHA/ACC guideline for the management of patients with valvular heart disease: a report 
of the American College of Cardiology/American Heart Association Task Force on Practice Guidelines. J Thorac Cardiovasc Surg 20142014;148:e1-e132.

4. Dunning J, Gao H, Chambers J, et al. Aortic valve surgery: marked increases in volume and significant decreases in mechanical valve use--an analysis of 41,227 patients over 5 years from the Society for Cardiothoracic Surgery in Great Britain and Ireland National database. J Thorac Cardiovasc Surg 2011;142:776-82.

5. Siregar S, de Heer F, Groenwold RH, et al. Trends and outcomes of valve surgery: 16-year results of Netherlands Cardiac Surgery National Database. Eur J Cardiothorac Surg 2014;46:386-97.

6. Isaacs AJ, Shuhaiber J, Salemi A, et al. National trends in utilization and in-hospital outcomes of mechanical versus bioprosthetic aortic valve replacements. J Thorac Cardiovasc Surg 2015;149:1262-9.

7. Antonucci E, Poli D, Tosetto A, et al. The Italian START-Register on anticoagulation with focus on atrial fibrillation. PLoS One 2015;10:e0124719.

8. Tripodi A, Poller L, Besselaar A, et al. A Proposed Scheme for Calibration of International Reference Preparations of Thromboplastin for the Prothrombin Time. Thromb Haemost 1995;74:1368-9.

9. Expert Committee on the Diagnosis and Classification of Diabetes Mellitus. Report of the expert committee on the diagnosis and classification of diabetes mellitus. Diabetes Care 2003;26(Suppl 1):S5-S20.

10. Palareti G, Leali N, Coccheri S, et al. Bleeding complications of oral anticoagulant treatment: an inception-cohort, prospective collaborative study (ISCOAT). Italian Study on Complications of Oral Anticoagulant Therapy. Lancet 1996;348:423-8.

11. Stassano P, Di Tommaso L, Monaco M, et al. Aortic valve replacement: a prospective randomized evaluation of mechanica versus biological valves in patients ages 55 to 70 years. $\mathrm{J} \mathrm{Am} \mathrm{Coll}$ Cardiol 2009;54:1862-8

12. Johnston DR, Roselli EE. Minimally invasive aortic valve surgery: Cleveland Clinic experience. Ann Cardiothorac Surg 2015;4:140-7.

13. Chiang YP, Chikwe J, Moskowitz AJ, et al. Survival and longterm outcomes following bioprosthetic vs mechanical aortic valve replacement in patients aged 50 to 69 years. JAMA 2014;312:1323-9.

14. Goldstone AB, Chiu P, Baiocchi M, et al. Mechanical or biologic prostheses for aortic-valve and mitral-valve replacement. $N$ Engl J Med 2017;377:1847-57.

15. Jamieson WR, Burr LH, Miyagishima RT, et al. Re-operation for bioprosthetic aortic structural failure - risk assessment. Eur J Cardiothorac Surg 2003;24:873-8.
16. Potter DD, Sundt TM, Zehr KJ, et al. Operative risk of reoperative aortic valve replacement. J Thorac Cardiovasc Surg 2005;129:94-103.

17. Dvir D, Webb JG, Bleiziffer S, et al. Transcatheter aortic valve implantation in failed bioprosthetic surgical valves. JAMA 2014;312:162-70.

18. Mylotte D, Andalib A, Thériault-Lauzier P, et al. Transcatheter heart valve failure: a systematic review. Eur Heart J 2015;36:1306-27.

19. Ye J, Cheung A, Yamashita M, et al. Transcatheter Aortic and mitral valve-in-valve implantation for failed surgical bioprosthetic valves: an 8-year single-center experience. JACC Cardiovasc Interv 2015;8:1735-44.

20. Akins CW, Miller DC, Turina MI, et al. Guidelines for reporting mortality and morbidity after cardiac valve interventions. Eur $J$ Cardiothorac Surg 2008;33:523-8.

21. Koertke H, Zittermann A, Tenderich G, et al. Low-dose oral anticoagulation in patients with mechanical heart valve prostheses: final report from the early self-management anticoagulation trial II. Eur Heart J 2007;28:2479-84.

22. Heneghan C, Ward A, Perera R, et al. Self-monitoring of ora anticoagulation: systematic review and meta-analysis of individual patient data. Lancet 2012;379:322-34.

23. Labaf A, Svensson $\mathrm{PJ}$, Renlund $\mathrm{H}$, et al. Incidence and risk factors for thromboembolism and major bleeding in patients with mechanical valve prosthesis: A nationwide population-based study. Am Heart J 2016;181:1-9.

24. Eikelboom JW, Brueckmann M, Van de Werf F. Dabigatran in patients with mechanical heart valves. N Engl J Med 2014;370:383-4.

25. Kirchhof P, Benussi S, Kotecha D, et al. 2016 ESC Guidelines for the management of atrial fibrillation developed in collaboration with EACTS. Europace 2016;18:1609-78.

26. Ageno W, Gallus AS, Wittkowsky A, et al. Oral anticoagulant therapy: Antithrombotic Therapy and Prevention of Thrombosis, 9th ed: American College of Chest physicians evidence-based clinical practice guidelines. Chest 2012;141(2 suppl):e44S-88.

27. Rosendaal FR, Cannegieter SC, van der Meer FJ, et al. A method to determine the optimal intensity of oral anticoagulant therapy. Thromb Haemost 1993;69:236-9.

28. Oake N, Fergusson DA, Forster AJ, et al. Frequency of adverse events in patients with poor anticoagulation: a meta-analysis. CMAJ 2007;176:1589-94.

29. Koertke $\mathrm{H}$, Minami $\mathrm{K}$, Bairaktaris $\mathrm{A}$, et al. INR self-management following mechanical heart valve replacement. $J$ Thromb Thrombolysis 2000;9(Suppl 1):41-5.

30. Kyrle PA, Eichinger S. Vitamin K antagonists: self-determination by self-monitoring? Lancet 2012;379:292-3. 